\section{Pneumonia and Methotrexate}

British Medical fournal, 1970, 2, 156

Methotrexate is commonly used in the treatment of acute lymphoblastic leukaemia. For maintenance therapy it was formerly given in continuous daily dosage, but in recent years it has been used in larger doses given twice weekly. Clarysse et al. (1969) described a severe respiratory illness in patients receiving intermittent methotrexate therapy and believed that it possibly represented an adverse reaction to the drug. The patient here described suffered from a similar illness while receiving methotrexate, further suggesting that this drug may cause acute pulmonary disease. It is important that this condition be recognized as a probable drug reaction. Intermittent methotrexate therapy is now being more widely used, and the complication is apt to be mistaken for a fulminant respiratory infection. It may respond dramatically to corticosteroid therapy.

\section{CASE History}

A 19-year-old woman was found to be suffering from acute lymphoblastic leukaemia in July 1968. Treatment was started with prednisone and vincristine, and when remission occurred these drugs were stopped and maintenance therapy was given with mercaptopurine. Though she remained in remission, this drug was also stopped after nine weeks and treatment was continued with methotrexate $21 \mathrm{mg}$./sq. m. body surface, being given intramuscularly twice weekly.

Twenty-eight weeks after starting methotrexate the patient became easily tired and increasingly breathless over a period of two days. She had a slight cough without, however, any sputum. In hospital she was noted to be dyspnoeic, cyanosed, and to have a pyrexia of $104^{\circ} \mathrm{F}$. $\left(40^{\circ} \mathrm{C}\right.$.). The blood pressure was $95 / 60 \mathrm{~mm}$. $\mathrm{Hg}$. Bilateral basal crepitations were heard in the chest. There was no wheezing. A chest $x$-ray film, however, showed widespread shadowing of both lung fields tending to become confluent in some areas. A blood count showed no evidence of leukaemic relapse, but there was an eosinophilia of $16 \%$ of a total white cell count of $3,600 /$ cu.mm. Treatment was started with streptomycin and cephaloridine. Because of the low blood pressure hydrocortisone and later prednisone were also given. There was rapid symptomatic improvement and the next day the temperature had fallen to normal.

A further chest $x$-ray film six days later showed complete clearing of both lung fields. On the seventh day, however, the temperature again rose to $101^{\circ} \mathrm{F}$. $\left(38.3^{\circ} \mathrm{C}\right.$.), despite continued antibiotic treatment. The prednisone dosage had been reduced from $30 \mathrm{mg}$. daily on the fourth day to $10 \mathrm{mg}$. daily at the time symptoms recurred. Treatment with both antibiotics and prednisone was stopped and the pyrexia continued for a further nine days, with some return of dyspnoea and shadowing on the chest $x$-ray film. The symptoms then settled and the chest $x$-ray appearances returned to normal.

In view of the eosinophilia and the rapid resolution of the $x$ ray changes when prednisone was given it was felt that the patient had an allergic pneumonia. A skin test for hypersensitivity to the fungus Aspergillus was negative. Sensitivity to methotrexate was also considered possible. Two further doses of this drug had been given during the first week after admission. After the patient had lost her symptoms a further dose of $10 \mathrm{mg}$. was given intramuscularly and she was closely observed. There was, however, no return of symptoms and the chest $x$-ray picture remained clear.
After discharge maintenance therapy for the leukaemia was changed to mercaptopurine. She remained in remission seven months after her respiratory illness and had had no recurrence of symptoms.

\section{COMMENT}

Clarysse et al. (1969) described a number of patients who suffered a severe but self-limited respiratory illness while receiving intermittent methotrexate, therapy. Lung biopsy in one patient showed the features of an allergic granulomatous pneumonia. They considered that the illness in these patients suggested, but did not establish, that the pneumonia was caused by methotrexate. The present patient gives further substance to the suspicion that this drug may cause an allergic pneumonia. She also suffered a respiratory illness with features suggestive of a pulmonary sensitivity reaction while receiving intermittent doses of methotrexate. There was no recurrence of symptoms when a test dose of methotrexate was given. This is consistent with the finding in the previous report that the acute phase of the illness was self-limited, regardless of whether or not methotrexate therapy was continued.

Pulmonary sensitivity may develop to a number of drugs, nitrofurantoin sensitivity giving rise to the most acute and severe reaction (Israel and Diamond, 1962). Generally, when sensitization to this drug occurs during a course of treatment, symptoms appear within 7 to 10 days and the condition resolves in about 24 hours after withdrawal of the drug. In contrast this patient had been receiving methotrexate for 196 days, and the illness lasted a total of 18 days and for nine days after withdrawal of the drug. The patients described by Clarysse et al. (1969) had been given methotrexate for up to 100 days, and the acute phase of their illness also lasted from 10 to 40 days.

Intermittent methotrexate therapy is now being more widely used in the treatment of leukaemia and it is important that this respiratory illness be recognized as a possible sensitivity reaction to the drug. It is apt to be mistaken for a severe bacterial infection in a patient with decreased resistance due to cytotoxic therapy. The eosinophilia in the peripheral blood and the disparity between the pronounced changes in the chest $x$-ray picture and the few abnormal signs on auscultation are helpful diagnostic features. In the case reported here prednisone produced rapid improvement.

\section{J. H. ROBERTSON; M.D., M.R.C.P.ED., M.R.C.PATH.,} Clinical Pathologist.

Belfast City Hospital, Belfast, BT9 7AD.

My thanks are due to Dr. R. W. Temple of Coleraine Hospital for referring the patient to me and for his helpful clinical observations.

\section{REFERENCES}

Clarysse, A. M., Cathey, W. J., Cartwright, G. E., and Wintrobe, M. M. (1969). Fournal of the American Medical Association, 209, 1861 . Israel, H. L., and Diamond, P. (1962). New England fournal of
Medicine, 266, 1024. 